\title{
Congenital Pulmonary Lymphangiectasis
}

\section{Report of 11 Examples with Special Reference to Cardiovascular Findings}

\author{
N. E. FRANCE and R. J. K. BROWN \\ From The Queen Elizabeth Hospital for Children, London
}

\begin{abstract}
France, N. E., and Brown, R. J. K. (1971). Archives of Disease in Childhood, 46, 528. Congenital pulmonary lymphangiectasis. The features of 11 cases of congenital pulmonary lymphangiectasis dying during the neonatal period are presented. Seven were associated with total anomalous pulmonary venous drainage with constriction of the common pulmonary vein at its junction with the general venous system. The anatomical features are compared with 14 infants with total anomalous pulmonary venous drainage without pulmonary lymphangiectasis.

Evidence from this series and from the published reports suggests that at least some examples of congenital pulmonary lymphangiectasis result from obstruction to the pulmonary venous return by anomalous pulmonary venous drainage or obstructive left heart anomalies. It is probable that congenital pulmonary lymphangiectasis will remain a bar to the successful surgical treatment in the newborn period of many patients with total anomalous pulmonary venous drainage.
\end{abstract}

The lungs of a newborn infant with congenital pulmonary lymphangiectasis (CPL) are bulky and firm with clearly defined lobulation, and sometimes show dilated lymph channels beneath the pleura and in the interlobular septa. Microscopically, increased connective tissue and dilated lymphatics are present in the subpleural tissue, interlobular septa, and peribronchial tissue throughout both lungs (Fig.). Since it was described first by Virchow in 1856, only 28 cases have been added to the literature. A noteable contribution was made by Laurence who, in 1955 and 1959, recorded a series of 10 infants with this condition. He observed that, in spite of the paucity of published reports, it is probably not rare but goes unrecognized especially in its microscopical form. This view is favoured by our experience.

During the period 1958 to 1970 inclusive, 826 stillbirths, 1289 infants under the age of 28 days, and 399 babies aged 1 to 12 months were examined post mortem. Among these there were 11 patients with CPL, in 7 of whom it was associated with total anomalous pulmonary venous drainage (TAPVD). The hearts of two examples in whom no cardiovascular anomalies were noted (Table I; Cases 1 and 4) were not available for re-examination so that

Received 8 February 1971. the presence of TAPVD cannot be excluded with certainty.

\section{Clinical Features}

The clinical picture in the most severely affected babies did not differ from respiratory distress in the newborn due to many other pulmonary causes except that it was not usually possible to relieve the cyanosis by providing high concentrations of oxygen in the inspired air. Shortly after birth it was noted that the baby's respiratory rate was over 60 a minute. There was an expiratory grunt and the external nares were flared. Cyanosis increased. There was indrawing of the chest on inspiration, associated with sternal retraction and intercostal recession. Usually fine or medium crepitations were audible, particularly at the lung bases. Before long in most cases the liver enlarged as evidence of congestive failure. Most of the babies had no cardiac murmur, and if a murmur were present it was rarely of any diagnostic assistance. In less severe cases symptoms were delayed for a few days, when reluctance to feed and sweating suggested the onset of cardiac failure. Thereafter, respiratory difficulty and cyanosis increased. In those patients in whom the pulmonary veins were connected with the portal system diarrhoea was a common symptom. The radiographic appearances of the lungs were always abnormal and sometimes very striking, varying from a generalized congestive pattern to one of diffuse reticulation interspersed with 


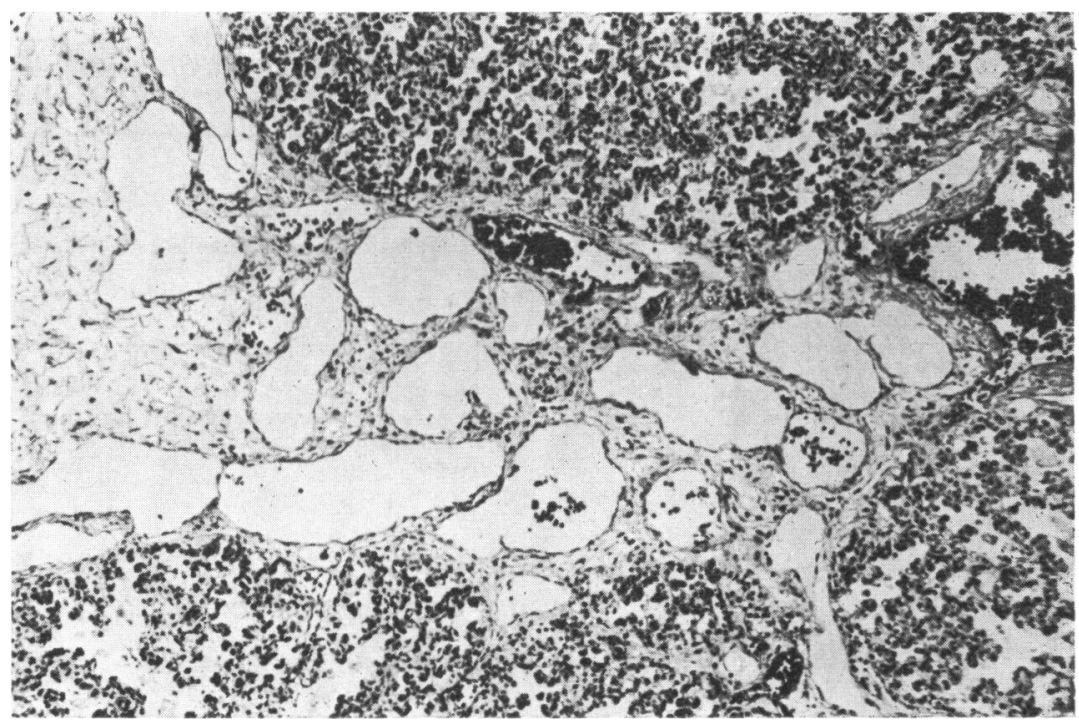

FIG.-Case 3. Photomicrograph of lung showing characteristic dilated lymph channels in interlobular septum. (Heidenhain's trichrome $\times 75$.)

small cystic areas, but the heart shadow was usually within normal limits. The electrocardiogram showed right axis deviation and right ventricular dominance consistent with the usual findings in the newborn baby, but occasionally right atrial hypertrophy was indicated by tall $\mathbf{P}$ waves, particularly in lead II.

\section{Case Reports}

Case 11 (TAPVD with CPL). A male, full-term normal delivery, birthweight $3.03 \mathrm{~kg}$ (a previous sib Case 9 had died at the age of 28 hours with TAPVD into the left innominate vein together with $\mathrm{CPL}$ ). He breathed and cried well at birth, but after 5 minutes he had a short cyanotic attack. He improved after being given oxygen in an incubator for a few hours and made good progress until the third day when he became breathless and cyanosed and would not feed. A chest $x$-ray suggested mild generalized atelectasis, but cyanosis persisted even in high concentrations of oxygen. At the age of $\mathbf{5}$ days, there was central and peripheral cyanosis, sweating, and rapid respirations (70 a minute). There was no clinical cardiac enlargement but there was a grade 3 ejection systolic murmur down the left sternal border, and the second sound in the pulmonary area was clearly split but obviously accentuated. The liver edge was $2.5 \mathrm{~cm}$ below the costal margin. The lungs were clear. A chest $x$-ray showed no cardiac enlargement but the lungs were diffusely congested. The electrocardiogram showed marked right axis deviation and right ventricular hypertrophy with moderate right atrial hypertrophy. A tentative diagnosis of TAPVD was made. His condition deteriorated and he died on the 14th day in spite of digitalization and diuretic therapy.

Necropsy showed that the pulmonary veins from both lungs joined to form a common trunk which passed through the oesophageal hiatus and entered the portal system at the junction of the portal vein and the ductus venosus where it was constricted to a diameter of $0.2 \mathrm{~cm}$. The lungs showed typical lymphangiectasis.

Case 19 (TAPVD without CPL). A male, birthweight $3.005 \mathrm{~kg}$, was born by caesarean section, because of a breech presentation, to a 34-year-old West Indian primigravida with multiple fibroids. He remained well for one week though he sucked poorly at the breast and his feeds were complemented by expressed breast milk. On the 9th day he was cyanosed, he had abdominal distension, and began to pass loose stools sometimes containing a little blood and mucus. His weight was $2.934 \mathrm{~kg}$, temperature $37^{\circ} \mathrm{C}$, pulse $136 / \mathrm{min}$, respirations $38 / \mathrm{min}$. There was no clinical cardiac enlargement, the pulses were normal, and there were no murmurs or abnormal signs in the chest. He was treated for gastroenteritis, but there was an abnormally rapid weight gain of $170 \mathrm{~g}$ during the next 2 days, and he developed generalized oedema, hepatomegaly, and some ascites. A chest $x$-ray showed slight cardiac enlargement and congested lung fields with a diffuse reticular pattern suggesting pulmonary lymphangiectasis. Electrocardiography showed right axis deviation and moderate right ventricular hypertrophy. It was obvious that he had congestive cardiac failure and the $x$-ray appearances made the diagnosis of TAPVD with pulmonary venous obstruction most likely. The occurrence of diarrhoea suggested that the pulmonary veins might be draining into the portal system. In spite of digitalization, diuretics, and restriction of salt intake, there was no real improvement and he died suddenly on the 16th day. 


\section{TABLE I}

Congenital Pulmonary Lymphangiectasis and Total Anomalous Venous Drainage in Series of 2514 Perinatal Deaths and Infants Dying under Age of 12 months During 1958 to 1970 Inclusive

\begin{tabular}{|c|c|c|c|c|c|c|c|}
\hline & $\operatorname{Sex}$ & Age at Death & 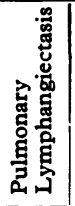 & $\begin{array}{l}\text { Pulmonary } \\
\text { Venous Drainage }\end{array}$ & 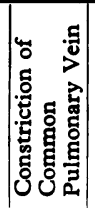 & Other Cardiovascular Anomalies & Anomalies of Other Viscera \\
\hline \multicolumn{8}{|c|}{ A. Pulmonary Lymphangiectasis with Normal Pulmonary Venous Drainage } \\
\hline 1 & $\mathbf{M}$ & $\mathbf{S B}$ & +1 & Lt. atrium & -1 & None & None \\
\hline 2 & $\mathbf{M}$ & $3 \mathrm{~min}$ & + & Lt atrium & - & $\begin{array}{l}\text { Atrioventricularis commune; } \\
\text { hypoplastic ductus arteriosus }\end{array}$ & Down's syndrome \\
\hline 3 & $\mathbf{F}$ & $25 \mathrm{~min}$ & + & Lt atrium & - & None & $\begin{array}{l}\text { Exomphalos; malrotation } \\
\text { of gut }\end{array}$ \\
\hline 4 & $\mathbf{M}$ & $9 \mathrm{hr}$ & + & Lt atrium & - & None & None \\
\hline \multicolumn{8}{|c|}{ B. Pulmonary Lymphangiectasis with Total Anomalous Pulmonary Venous Drainage } \\
\hline 5 & $\mathbf{F}$ & $6 \mathrm{hr}$ & +1 & Lt innominate & +1 & $\begin{array}{l}\text { Ostium secundum; atrioventri- } \\
\text { cularis commune }\end{array}$ & $\begin{array}{l}\text { Transposition of abdom- } \\
\text { inal viscera; agenesis } \\
\text { of spleen }\end{array}$ \\
\hline 6 & $\mathbf{F}$ & $11 \mathrm{hr}$ & + & Azygos & + & $\begin{array}{l}\text { Dextrocardia; atrioventicularis } \\
\text { commune; Pulmonary stenosis }\end{array}$ & $\begin{array}{l}\text { Transposition of viscera; } \\
\text { agenesis of spleen }\end{array}$ \\
\hline 7 & $\mathbf{M}$ & $14 \mathrm{hr}$ & + & Rt superior vena cava & + & None & None \\
\hline 8 & $\mathbf{M}$ & $27 \mathrm{hr}$ & + & Coronary sinus & + & $\begin{array}{l}\text { Mitral atresia, ventricular septal } \\
\text { defect; preductal coarctation }\end{array}$ & $\begin{array}{l}\text { Meckel's diverticulum; } \\
\text { talipes equinovarus }\end{array}$ \\
\hline 9 & $\mathbf{M}$ & $28 \mathrm{hr}$ & + & Lt innominate & + & None & None \\
\hline 10 & $\mathbf{M}$ & $31 \mathrm{hr}$ & + & Azygos & + & Ostium secundum & None \\
\hline 11 & M & $14 \mathrm{dy}$ & + & Ductus venosus & + & None & None \\
\hline \multicolumn{8}{|c|}{ C. Total Anomalous Pulmonary Venous Drainage without Pulmonary Lymphangiectasis } \\
\hline 12 & F & $15 \mathrm{~min}$ & -1 & Rt superior vena cava & $1-1$ & $\begin{array}{l}\text { Ostium secundum; ventricular } \\
\text { septal defect; mitral atresia; } \\
\text { pulmonary stenosis }\end{array}$ & $\begin{array}{l}\text { Rectal atresia; cleft lip } \\
\text { and palate; } \\
\text { polydactyly }\end{array}$ \\
\hline 13 & $\mathbf{F}$ & $57 \mathrm{hr}$ & - & Ductus venosus & + & Ostium secundum & None \\
\hline 14 & $\mathbf{M}$ & $3 \mathrm{dy}$ & - & Coronary sinus & - & $\begin{array}{l}\text { Hypoplastic lt heart; single } \\
\text { atrium; aortic stensosis }\end{array}$ & $\begin{array}{l}\text { Ellis-van Creveld } \\
\text { Syndrome }\end{array}$ \\
\hline 15 & $\mathbf{M}$ & $4 \mathrm{dy}$ & - & Coronary sinus & - & Ostium secundum & Oesophageal atresia \\
\hline 16 & $\mathbf{F}$ & $5 \mathrm{dy}$ & - & Portal vein & - & $\begin{array}{l}\text { Ostium secundum: ventricular } \\
\text { septal defect; transposition of } \\
\text { aortic valve }\end{array}$ & Lt hydroureter \\
\hline 18 & $\mathbf{M}$ & 14 dy & - & Rt superior vena cava & - & None & None \\
\hline 19 & $\mathbf{M}$ & $16 \mathrm{dy}$ & - & Portal vein & - & None & None \\
\hline 20 & $\mathbf{M}$ & 5 wk & - & Coronary sinus & - & None & None \\
\hline 21 & $\mathbf{F}$ & $3 \mathrm{mth}$ & - & Lt innominate & - & None & None \\
\hline 22 & $\mathbf{M}$ & 5 mth & - & Rt superior vena cava & - & $\begin{array}{l}\text { Ostium secundum; atrioventri- } \\
\text { cularis commune; pulmonary } \\
\text { stenosis; transposition of } \\
\text { aortic valve }\end{array}$ & $\begin{array}{l}\text { Agenesis of spleen; } \\
\text { malrotation of gut }\end{array}$ \\
\hline 23 & $\mathbf{M}$ & $9 \mathrm{mth}$ & - & Coronary sinus & - & None & None \\
\hline 24 & $\mathbf{F}$ & $10 \mathrm{mth}$ & - & Lt innominate & - & Cor triatriatum & None \\
\hline 25 & & $11 \mathrm{mth}$ & - & Coronary sinus & - & $\begin{array}{l}\text { Ostium secundum; pulmonary } \\
\text { stenosis }\end{array}$ & None \\
\hline
\end{tabular}

Cases 1, 4, and 8 were summarized in an addendum to the paper by Laurence (1959).

Necropsy confirmed the presence of TAPVD with all the pulmonary veins draining into a common trunk which passed through the oesophageal hiatus and entered the portal vein. There was no venous constriction and no CPL.

\section{Pathological Features}

In Cases 5 to 11, CPL was associated with drainage of all pulmonary veins into a common vein and thence into the superior vena cava, left innominate vein, azygos vein, coronary sinus, or ductus venosus (Table II). $\quad 38 \%$ of all infants with supradiaphragmatic TAPVD had associated CPL contrasting with $20 \%$ where drainage was infradiaphragmatic.

In all infants with associated CPL and TAPVD (Cases 5 to 11) the common pulmonary vein was constricted at its junction with the general venous system, often to a diameter of about $0.1 \mathrm{~cm}$ (Table I). This contrasted with the finding of only two examples of narrowing among 14 cases of TAPVD without CPL.

Four examples of CPL displayed TAPVD with additional cardiac anomalies. Cases 5 and 6 had 
TABLE II

Total Anomalous Pulmonary Venous Drainage in Series of 2514 Perinatal Deaths and Infants Dying under Age of 12 months during 1958 to 1970 Inclusive

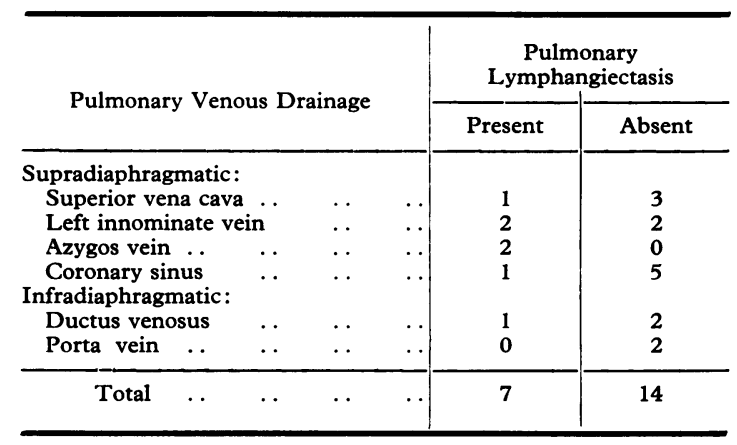

additional severe anomalies of the heart accompanied by transposition of viscera and agenesis of the spleen. Case 8 had multiple cardiac anomalies with minor anomalies of other organs while Case 10 had an ostium secundum defect only. Additional cardiovascular lesions occurred in over half of all the cases of TAPVD in the series, and there was no significant difference in their frequency or severity whether pulmonary lymphangiectasis was present or not. Case 2 was the only example where CPL was associated with cardiac anomalies which did not include TAPVD.

\section{Discussion}

No cardiovascular anomalies were noted in 15 of 28 necropsies of CPL (Virchow, 1856; Klebs, 1889; Smith, 1925; Laurence, 1955: Cases 1 and 2; Laurence, 1959: Cases 3, 9, and 10; Frank and Piper, 1959: Cases 1 and 2; Heumann, Korn, and Lévy-Silagy, 1960; Moffat, 1960: Case 5; Carter and Vaughn, 1961; Ekelund, Palmstierna, and Östberg, 1966; Fronstin et al., 1967). The anatomy of the pulmonary veins was mentioned in only 5 cases; 2 infants recorded by Le Tan-Vinh, Cochard, and Vu Trieu Dong (1964) had TAPVD associated with other cardiac anomalies, while their Case 1 had anomalous drainage of only the superior left pulmonary vein together with hypoplasia of the left ventricle and ascending aorta. It is possible that the unexplained right ventricular hypertrophy observed by Bredt (1952) and Laurence (1959, Case 5) was due to TAPVD. Maidman and Barnett (1957) suggested that right ventricular hypertrophy resulted from stiffening of the lungs by the dilated lymphatics, while in one infant (Moffat, 1960 , Case 7) it was associated with a ventricular septal defect. All other recorded cases with cardiovascular anomalies were varieties of the hypoplastic left heart syndrome (Laurence, 1955, 1959;
Giammalvo 1955; Sacrez et al., 1960; present series, Case 8).

As TAPVD is easily missed at necropsy, it is likely that it existed at least in some of the 21 examples where no cardiovascular anomalies were recorded.

There was a remarkably high incidence of agenesis of the spleen, all 4 examples of which had TAPVD (Le Tan-Vinh et al., 1964: Cases 2 and 3; present series Cases 4 and 5). In only 2 cases has lymphangiectasis been found outside the lungs (Heumann et al., 1960; Ekelund et al., 1966). There were single examples of cretinism (Virchow 1856), arachnodactyly (Laurence, 1955, Case 2), multiple anomalies suggestive of trisomy 13 (Laurence, 1959, Case 6), non-Rh hydrops fetalis (Frank and Piper, 1959, Case 2), and exomphalos (present series Case 2).

Most authors have regarded CPL as a primary developmental anomaly. Giammalvo (1955) thought that there was delay in linkage of isolated lymphatic spaces, but Laurence (1955, 1959) considered that there was continual growth of the lungs with the tissue elements maintaining the proportions observed at 16 weeks' gestation. Obstruction of major lymph channels has never been recorded but only Heumann et al (1960) appear to have made a special attempt at its demonstration. Sacrez et al. (1960) considered that haemodynamic factors resulting from hypoplastic left heart syndrome without ventricular septal defect could have produced the pulmonary changes in their patient. Maidman and Barnett (1957) found no obstruction of the pulmonary veins and Le Tan-Vinh et al. (1964) did not record any narrowing of veins in their 2 cases of TAPVD. Our finding of TAPVD with constriction of the common pulmonary vein in 7 infants with CPL suggests that obstruction to the venous outflow from the lungs is a major factor in the pathogenesis of this condition. Since only one of the babies survived beyond the second day of life, it must be assumed that the obstruction of venous return has been important at least during the later part of fetal life.

The present series shows that CPL is liable to cause death during the first 2 days of life and must be considered to be a major cause of death during the neonatal period of babies born with TAPVD. The ages of cases reported are not significantly different from the present series. 22 of 29 recorded infants were stillborn or died within 2 days of birth. 6 infants survived for 8 days to 10 weeks, 1 lived for 16 months, and 1 child (Javett, Webster, and Braudo, 1963) diagnosed by lung biopsy, was still alive at 9 months of age. 
Of 38 infants where the sex was known, 25 were male, giving a $M: F$ ratio of about $2: 1$. Cases 9 and 11 in the present series were sibs born at an interval of 13 months. It is noted that, though both had TAPVD, the junction with the general venous system differed. Gathman and Nadas (1970) in a survey of 75 cases of TAPVD found 2 sibs.

In the more severe examples, a chest $x$-ray shows a diffuse reticular pattern interspersed with small cystic areas and is, in fact, one example of so-called 'honeycomb lung'. In less extreme cases the $x$-ray picture shows only a diffuse congestive pattern very similar to that of pulmonary venous congestion seen in babies with obstruction to the pulmonary venous return associated with such lesions as TAPVD or obstructive left heart anomalies like mitral atresia. In Case 19 the chest $x$-ray suggested CPL but it was not confirmed post mortem. Indeed, the $x$-ray appearances support the view that severe pulmonary venous obstruction may be the precursor of CPL. From the $x$-ray of the thorax it is not possible to make a confident diagnosis and, since congenital heart disease, especially TAPVD, is a possibility, nothing is to be lost by carrying out urgent angiography. If there is good evidence of pulmonary venous obstruction, it seems possible that the condition would be improved by removing any additional obstruction by atrial septostomy. Serratto et al. (1968) claimed improvement from balloon septostomy in cases of TAPVD, but Gathman and Nadas (1970) emphasized that this procedure could not be expected to help patients with pulmonary venous obstruction as by kinks or narrowing of the common pulmonary vein. They believed that this procedure could delay an aggressive surgical approach too long. While such an approach may be justified on the grounds that conservative therapy gives no chance of prolonged survival, it is probable that the presence of CPL will always be a bar to success in the more severe examples of TAPVD.

We are indebted to Mrs. F. M. Byron for her technical assistance.
REFERENCES

Bredt, H. (1952). Lymphangiectasia pulmonum congenita. Virchows Archiv für pathologische Anatomie, und Physiologie und für Klinische Medizin, 321, 517.

Carter, R. W., and Vaughn, H. M. (1961). Congenital pulmonary lymphangiectasis. Report of a case with roentgen findings. American fournal of Roentgenology, Radium Therapy, and Nuclear Medicine, 86, 576.

Ekelund, H., Palmstierna, S., and Ostberg, G. (1966). Congenital pulmonary lymphangiectasis. Acta Paediatrica Scandinavica, $55,121$.

Frank, J., and Piper, P. G. (1959). Congenital pulmonary cystic lymphangiectasis. Fournal of the American Medical Association, 171, 1094.

Fronstin, M. H., Hooper, G. S., Besse, B. E., and Ferreri, S. (1967). Congenital pulmonary cystic lymphangiectasis-case report and a review of 32 cases. American fournal of Diseases of Children, 114, 330.

Gathman, G. E., and Nadas, A. S. (1970). Total anomalous pulmonary venous connection: clinical and pinysiologic observations of 75 pediatric patients. Circulation, $42,143$.

Giammalvo, J. T. (1955). Congenital lymphangiomatosis of the lung; a form of cystic disease. Laboratory Investigation, 4, 450.

Heumann, G., Korn, R., and Lévy-Silagy, J. (1960). A propos d'un cas de lymphangiectasies pulmonaires congénitales. Archives Francaises de Pediatrie, 17, 1012.

Javett, S. N., Webster, I., and Braudo, J. L. (1963). Congenital dilatation of the pulmonary lymphatics. Pediatrics, 31, 416.

Klebs, E. (1889). Die allgemeine Pathologie, vol. 2, p. 335. Fischer, Jena.

Laurence, K. M. (1955). Congenital pulmonary cystic lymphangiectasis. Fournal of Pathology and Bacteriology, 70, 325.

Laurence, K. M. (1959). Congenital pulmonary lymphangiectasis. fournal of Clinical Pathology, 12, 62.

Maidman, L., and Barnett, R. N. (1957). Congenital dilatation of pulmonary lymphatics. Archives of Pathology, 64, 104.

Moffat, A. D. (1960). Congenital cystic disease of the lungs and its classification. Fournal of Pathology and Bacteriology, 79, 361 .

Sacrez, R., Levy, J. M., Korn, R., and Paira, M. (1960). Lymphangiectasies pulmonaires congénitales avec fibroélastose de l'endocarde. Archives Françaises de Pediatrie, 17, 1344.

Serratto, M., Bucheleres, H. G., Bicoff, P., Miller, R. A., and Hastreiter, A. R. (1968). Palliative balloon atrial septostomy for total anomalous pulmonary venous connection in infancy. Fournal of Pediatrics, 73, 734.

Smith, S. (1925). Congenital cystic disease of the lungs. British Medical fournal, 1, 1005.

Le Tan-Vinh, Cochard, A. M., and Vu Trieu Dong (1964). Lymphangiectasies pulmonaires congénitales et lymphangite pleuro-pulmonaire cancéreuse métastatique de l'enfant. Archives Franfaises de Pediatrie, 21, 165.

Virchow, R. (1856). Gesammelte Abhandlungen zur wissenschaftlichen Medicin, p. 982. Meidinger, Frankfort.

Correspondence to Dr. N. E. France, The Queen Elizabeth Hospital for Children, Hackney Road, London E.2. 